\title{
Los rostros de la solidaridad. Historia Oral y Vida Cotidiana. El discurso existencial de los exiliados chilenos en México y María Esther Zuno de Echeverría*
}

\author{
The faces of solidarity, Oral History and Everyday Life. \\ The existential discourse of Chileans exiled in Mexico \\ and Maria Esther Zuno de Echeverria
}

Os rostos da solidariedade. História Oral e Vida quotidiana. $O$ discurso existencial dos exiliados chilenos no México e Maria Esther Zuno de Echeverría

Recibido el 29 de marzo de 2015. Aceptado el 4t de noviembre de 2015.

, Para citar este artículo:

Valles Ruiz, Rosa María y

Castelli Olvera, Azul Kikey

(diciembre, 2015). Los rostros de la solidaridad. Historia Oral

y Vida Cotidiana. El discurso

existencial de los exiliados

chilenos en México y María

Esther Zuno de Echeverría.

Ánfora, 22(39), 125-146.

Universidad Autónoma de

Manizales. ISSN 0121-6538.

\author{
Rosa María Valles Ruiz* \\ México \\ Azul Kikey Castelli Olvera** \\ México
}

\section{Resumen}

Objetivo: identificar las características del discurso relacionado con la solidaridad hacia los chilenos exiliados en México, tras el golpe de Estado al presidente Salvador Allende en 1973. También se estudia la relevancia de la

\footnotetext{
* Este artículo se deriva de una investigación en proceso sobre Los exilios en América Latina y el discurso de la solidaridad en vinculación con las líneas de investigación Análisis de discurso e Historia oral que trabajan las autoras en la Universidad Autónoma del Estado de Hidalgo.

** Doctora en Ciencias Políticas y Sociales. Magíster en Ciencias de la Comunicación. Licenciada en Ciencia Política y Administración Pública. Profesora-Investigadora en la Universidad Autónoma del Estado de Hidalgo.Correo electrónico: vallezcurdia@gmail.com mvalles@uaeh.edu.mx

** Doctora en Ciencias Sociales. Magíster en Ciencias de la Comunicación. Licenciada en Ciencias de la Comunicación. Profesora de la Universidad Autónoma del Estado de Hidalgo, Correo electrónico: sakuntala83@yahoo.com.mx
} 
política de asilo del gobierno mexicano y la postura de solidaridad de María Esther Zuno, que facilitó la adaptación de los exiliados a México. Metodología: enfoque cualitativo con registro documental sobre los exilios de la década de los setenta y las características de la política de asilo del gobierno de México. Se utilizó la metodología de la historia oral, concretamente el testimonio y el relato de chilenos, para analizar el discurso y la reconstrucción de significados de quienes llegaron al país. El análisis de discurso se hizo con base en las categorías planteadas por Daniel Prieto Castillo (indicación, exhortación, explicación y valoración, vinculadas a la situación personal que vivieron los exiliados y su ingreso al país. Resultados: la inserción de los chilenos exiliados a la sociedad mexicana, tras el golpe de Estado de Augusto Pinochet en Chile, fue favorecida por la política de asilo del gobierno mexicano y el ejercicio del poder "de facto" de María Esther Zuno. La resignificación de los testimonios destacaron la explicación y la valoración de dos coyunturas históricas destacadas: una institucional (la política de asilo de México) y una personal (la política del poder de facto de la señora Zuno). Conclusiones: aunado a la política de asilo del gobierno mexicano hubo un discurso de solidaridad hacia los chilenos. La política de asilo del gobierno mexicano fundamentado en las Convenciones de La Habana (1928), Montevideo (1933) y Caracas (1954), de las cuales México fue signatario, constituyó un elemento fundamental en el ingreso de los chilenos que se exiliaron en México.

Palabras clave: Discurso de solidaridad, Análisis del discurso, Exilio chileno, Poder de facto, Política mexicana de asilo.

\section{Abstract}

Objective: To identify characteristics of the discourse related to solidarity with Chileans exiled in Mexico after the coup d'état against President Salvador Allende in 1973. The relevance of the asylum policy of the Mexican government and the solidarity position of Maria Esther Zuno, who facilitated the adaptation process of the Chilean exiles in Mexico are studied as well. Methodology: Qualitative approach with documentary records about the exiles of the seventies and the characteristics of the asylum policy of Mexico. The oral history methodology, particularly testimonies and stories of Chileans, were used for discourse analysis and meanings reconstruction of those who arrived in Mexico. Discourse analysis was based on the categories stated by Daniel Prieto Castillo (indication, exhortation, explanation, and valuation) and linked to personal situations experienced by exiles and their entry into Mexico. Results: The incorporation of Chileans exiles into the Mexican society, after the coup d'état against Augusto Pinochet in Chile, was favored by the asylum policy of the Mexican government and the exercise of the de facto power of Mary Esther Zuno. The new 
meaning of the testimonies emphasized the explanation and valuation of two noted historical crises: one institutional (asylum policy of Mexico) and one personal (de facto power policy of Ms. Zuno). Conclusions: There was a discourse of solidarity with the Chileans along with the asylum policy of Mexico. The asylum policy of Mexico based on the Conventions of La Habana (1928), Montevideo (1933) and Caracas (1954), to which Mexico was signatory, was a key issue in the Chileans exiles entry into Mexico.

Keywords: Discourse of Solidarity, Discourse Analysis, Chilean Exile, De Facto Power, Asylum Policy of Mexico.

\section{Resumo}

Objetivo: identificar as características do discurso relacionado com a solidariedade para com os chilenos exiliados no México, após do golpe de Estado ao presidente Salvador Allende em 1973. Também se estuda a relevância da política de asilo do governo mexicano e a postura de solidariedade de Maria Esther Zuno, que facilitou a adaptação dos exiliados ao México. Metodologia: enfoque qualitativo com registro documental sobre os exílios da década dos setenta e as características da política de asilo do governo do México. Utilizou-se a metodologia da história oral, concretamente o testemunho e o relato de chilenos, para analisar o discurso e a reconstrução de significados daqueles que chegaram ao país. A análise de discurso se fez com base nas categorias expostas por Daniel Prieto Castillo (indicação, exortação, explicação e valoração, vinculadas à situação pessoal que viveram os exiliados e sua entrada ao país). Resultados: a inserção dos chilenos exiliados à sociedade mexicana, depois do golpe de Estado de Augusto Pinochet no Chile, foi favorecida pela política de asilo do governo mexicano e o exercício do poder "de facto" de Maria Esther Zuno. A ressignificação dos testemunhos destacaram a explicação e a valoração de duas conjunturas históricas destacadas: uma institucional (a política de asilo do México) e uma pessoal (a política do poder de facto da senhora Zuno). Conclusões: unido à política de asilo do governo mexicano teve um discurso de solidariedade para os chilenos. A política de asilo do governo mexicano fundamentado nas Convenções da Habana (1928), Montevideo (1933) e Caracas (1954), das quais México foi signatário, constituiu um elemento fundamental na entrada dos chilenos que se exiliaram no México.

Palavras chave: Discurso de solidariedade, Análise do discurso, Exilio chileno, Poder de facto, Política mexicana de asilo. 


\section{Introducción}

El exilio es algo curiosamente cautivador sobre lo que pensar, pero terrible de experimentar. Es la grieta imposible de cicatrizar impuesta entre un ser humano y su lugar natal..., entre el yo y su verdadero hogar: nunca se puede superar su esencial tristeza.

Edward Said. Reflexiones sobre el exilio: ensayos literarios y culturales

Este trabajo estudia el contexto histórico en el que se inscribieron los exilios en el mundo en la década de los setenta del siglo XX. Se hace énfasis en el registrado en México en 1973, cuando alrededor de 4 mil chilenos (Elías, 2007, pp. 146-147) llegaron a México tras el golpe de Estado en Chile por parte del general Augusto Pinochet al presidente Salvador Allende. Enseguida, se abordan las características de la política de asilo en México. Posteriormente, se hace referencia a la importancia de la vida cotidiana de las personas y la incidencia en ésta de las acciones concretas realizadas desde el gobierno mexicano para la adaptación de los exiliados chilenos. Se registrarán, asimismo, los testimonios de los chilenos sobre sus experiencias en México y el trato que recibieron.

En el orbe, la década de los setenta se vivió de diversas maneras. La polarización Estados Unidos-Unión Soviética entró en un periodo de distensión y "algunos hechos [...] parecieron inclinar la balanza hacia uno de los bloques contrapuestos y, además, generar un clima de optimismo dentro del mundo progresista y de las izquierdas" (Rojas 2014, p. 3). Acontecimientos como el final de la guerra de Vietnam, en 1975, no modificaron la evolución de la Guerra Fría. Otros eventos airearon el ambiente político, como los procesos de liberación en África, Asia y América Latina "que encontraron un aliado en el bando soviético" (Rojas 2014, p. 3). Además, se registró la llamada Revolución de los Claveles en Portugal en 1974. Rojas (2014) incluye también la instalación de regímenes revolucionarios en Angola, Mozambique, Guinea Bissau y Cabo Verde, la caída de la dictadura militar de derecha en Grecia e incluso la muerte de Francisco Franco en España que dio paso al proceso de transición de la democracia en el país ibérico. Menciona también la revolución en Irán y la invasión de las tropas soviéticas en Afganistán (1979) para concluir que "el péndulo de la historia mundial se inclinaba hacia la izquierda en la década de los setenta” (p. 4). 
Pese a este panorama esperanzador, en América Latina, la perspectiva era ominosa en algunos países, sobre todo del Sur, en los cuales se registró la militarización de la vida pública y, paralelamente, "se puso en marcha una maquinaria genocida que elevó al rango de políticas de Estado prácticas generalizadas de represión y exterminio" (Meyer y Salgado, 2002, p. 13).

Para analistas como Gala (1985, p. 71), la década de los setenta fue un largo Miércoles de Ceniza expresado en altos niveles de intolerancia y discriminación. Meyer y Salgado (2002) advierten que los años convulsos de América Latina se registraron también en el Caribe y se ubicaron desde el umbral de la segunda mitad del siglo XX. Atribuyen esa situación a una política deliberada de Estados Unidos calificada como "solidaridad continental" y de "seguridad nacional", las cuales propiciaron "la formación de gobiernos militares y dictatoriales como una supuesta medida para terminar con el comunismo" (p. 45).

El golpe de Estado y la transmisión del poder a las dictaduras militares se convirtieron en instrumento habitual para el derrocamiento de gobiernos democráticos... Invocando un pretendido interés público, se practicaron ejecuciones sumarias, torturas, secuestros, detenciones y asesinatos masivos como medida para frenar las protestas populares... (Meyer y Salgado, p. 45).

Meyer y Salgado (2002, p. 46) repasan los casos de Guatemala en 1954, 1957, de 1958 a 1962, de 1978 a 1982, años en los cuales México se convirtió en un refugio seguro. También de El Salvador, donde la situación en 1972, derivada de los conflictos electorales, determinó la salida de políticos destacados como José Napoleón Duarte, del Partido Demócrata Cristiano, quien se exilió. Otros países militarizados como Haití, República Dominicana, Brasil, vivieron etapas de tortura, violencia y angustia, lo cual provocó el exilio de sus ciudadanos hacia otros países, entre ellos México.

En Argentina, Jorge Rafael Videla asestó un golpe de Estado el 24 de marzo de 1976 al gobierno presidido por Estela Martínez de Perón, el cual derivó en una represión sangrienta secundada posteriormente por otros generales, situación que duró hasta 1983.

El panorama regional era inquietante. Sin embargo, también en esa década se registraron matices de esperanza: en Chile, llegó al poder Salvador Allende, tras integrar un grupo de organizaciones progresistas denominada "Unidad Popular". Allende planteó la instauración del Socialismo por la vía pacífica. Una de las primeras medidas de su gobierno fue la nacionalización del cobre. 
Empero, la viabilidad del camino propuesto se vio truncado el 11 de septiembre de 1973 cuando recibió el golpe militar de Augusto Pinochet, apoyado por la Agencia Central de Inteligencia de Estados Unidos de Norteamericana (CIA). Al asesinato del presidente chileno siguió una persecución despiadada y reclusión en campos de concentración de los chilenos leales a Allende.

Para José del Pozo (2004), el golpe de Estado de Pinochet y la instauración de la dictadura militar provocó la salida masiva de chilenos obligados a dejar su país por razones políticas. El destino fue Argentina, Venezuela, Estados Unidos, Suecia, Canadá, África y México, sobre todo. Las cifras de exiliados difieren según los autores. Los datos sobre el número de chilenos que salieron de su país por razones políticas siguen imprecisos. Para Rojas y Santoni (2013, 124), la gran mayoría eran militantes y simpatizantes de la Unidad popular (UP) y del Movimiento de Izquierda Revolucionario (MIR). Estos mismos autores citan datos de Amnistía Internacional registrados en el Archivo Digital de la Casa de Chile en México, que estiman que para junio de 1974, 150 mil chilenos estaban en el exilio.

Rojas y Santoni distinguen tres grandes segmentos hacia donde pidieron asilo los chilenos: América Latina, Europa Occidental y Europa del Este. La posibilidad de exiliarse en otros países latinoamericanos, señalan, "fue restringida”. Rojas y Santoni (2013) Citan a S. Dutrenit y amplían:

Muchos países de la región se encontraban o se iban a encontrar bajo dictaduras militares análogas a la pinochetista, las cuales se asociaron en la implementación de una política de represión llamada Operación Cóndor. En los países que podían acoger a los exiliados, esta realidad tuvo un peso mayor en resignificar la misma acción de solidaridad, debido a la percepción inmediata de una lucha común contra la violenta oleada represiva desencadenada por las dictaduras militares (Rojas y Santoni, 2013, p. 128).

El gobierno de la Unidad Popular, observan estos autores, fue percibido en algunas naciones como "patriótico y nacional” por cortar los vínculos con el capital estadunidense y que este imaginario fue sostenido "por gobiernos, sectores y hombres políticos tan ideológicamente lejanos como el régimen del Partido Revolucionario Institucional (PRI) en México y el peronismo argentino” (Rojas y Santoni, 2013, p. 128).

La llegada de los chilenos a México fue, sobre todo, a través de la embajada de México en Chile. Gonzalo Martínez Corbalá, quien fungió como embajador de México en Chile, desempeñó un papel destacado. Afirmó que en los momentos 
culminantes México dio refugio a 2400 familias chilenas y la suma total llegó a 10 mil personas, aunque posteriormente hubo una redistribución y se fueron a otros lugares a cumplir funciones políticas y otras más o "menos comprometidas" regresaron a Chile (Yankelevich y Tarrés, 1998, p. 128). Por su parte, Elías (2007, pp. 146-147), estima en 4 mil el número de chilenos que llegaron a México.

Yankelevich y Tarrés (1998, p. 128) estiman en 2 mil las familias que se quedaron en México. De hecho, el de México, afirman fue "un exilio pequeño" caracterizado por tres componentes:

Los que solicitaron y obtuvieron directamente el asilo diplomático en los recintos de la embajada de México en Santiago (80 o 85 por ciento); luego los que vinieron en dos vuelos especiales de prisioneros de guerra en 1975; un tercer componente marginal en el caso chileno lo constituyó un grupo de personas que fueron invitadas u obtuvieron por conductos especiales una visa, habitualmente por razones de alta excelencia profesional o académica, luego de solicitudes de universidades u otras instituciones mexicanas de educación superior. (Yankelevich y Tarrés, 1998, p. 129)

Tras la persecución de Augusto Pinochet contra los allendistas, la diáspora de chilenos fue abrupta y desesperada, como lo demuestran los testimonios de chilenos que salieron a diferentes países del orbe: Noruega, Argentina, Canadá, Suecia, Inglaterra, México.

¿Cómo se dio la llegada a México? ¿Cuáles fueron las condiciones laborales y de refugio que encontraron? ¿Cuál era el contexto socio-político de la época? ¿Cuál era la situación en México en 1973?

En la historia reciente de México se ubica el asilo a los españoles republicanos como uno de los hechos más relevantes de la política de asilo implementada por el presidente Lázaro Cárdenas. Fernando Serrano Migallón, citado por Meyer y Salgado (2002) señala que "la política mexicana de asilo no fue uniforme a lo largo de los seis años que comprendió ese periodo presidencial. La especial predisposición del general Cárdenas, a favor, por ejemplo, de los refugiados españoles, contrastaba con la política de asilo que se dio a los alemanes o sobre todo a los judíos" (p. 31).

El exilio de los españoles es el más significativo de la primera mitad del siglo XX en México, en tanto que el chileno representa un hito de la década de los setenta. Los demás exilios, con características peculiares, no alcanzaron la magnitud de los dos mencionados. 
En cualquier caso, el exilio se considera como una respuesta de los Estados a situaciones límite que viven los seres humanos. Desde el punto de vista teórico, señala Marina Franco, citada por Rojas (2014), la historia engloba de manera general en las categorías de Migración política y Exilio (s) políticos estos casos, aunque pone menos énfasis en "la especificidad de los sujetos y la experiencia de los sujetos" (p. 5).

La experiencia de los exilios reviste una importancia nacional e internacional, porque esa problemática está vinculada estrechamente con la validez y legitimidad de diversas estructuras sociales cuyas resquebrajaduras han expulsado prácticamente a voces políticas disidentes, como ocurrió en diversas dictaduras del cono sur latinoamericano. Rojas y Santoni (2013, pp. 123-142) consideran que los extremos que registraron los exilios en el siglo XX constituyeron a esa centuria en "una verdadera metáfora" y que en el ámbito latinoamericano se conoció "de cerca" ese trauma.

Por otra parte, abordar los rostros de la solidaridad que han recibido los exiliados en diversos países nos acerca a otra faceta del exilio, la que incide en la vida cotidiana de las personas que se ven obligadas a dejar sus países de origen.

En este contex to es relevante analizar el discurso de los exiliados. Las huellas de la solidaridad y la forma como ésta se manifestó indican una problemática poco estudiada: la experiencia de ingresar a un país hasta entonces desconocido en costumbres, tradiciones, formas de vivir. A través de los testimonios se pudo ir al encuentro de las respuestas a esas interrogantes.

Se estima, en principio, que la cotidianidad de los chilenos exiliados se facilitó en México por dos elementos clave: la política de asilo del gobierno mexicano y la solidaridad expresada directamente por María Esther Zuno ${ }^{1}$, quien ejercía un poder de facto, es decir, una influencia en el terreno de los hechos.

\footnotetext{
1. María Esther Zuno de Echeverría (Jalisco, 1924; Distrito Federal,1999) nació en el seno de una familia de clase media. Hija de José Guadalupe Zuno y Carmen Arce. Su padre, de formación juarista, impulsó de manera determinante la educación en Jalisco, entidad de la que llegó a ser gobernador. En su gestión creó la Universidad de Guadalajara. Impulsó el desarrollo artístico y apoyó la capacitación a nivel popular. Anticlerical, José Guadalupe Zuno participó contra la Rebelión Cristera en 1926. La influencia familiar y las ideas de su padre fueron fundamentales en la conformación de la personalidad e ideología de María Esther Zuno. Al casarse con Luis Echeverría Álvarez, quien llegó a la Presidencia de México en el sexenio 19701976, instrumentó una política social considerada como la más trascendental de la historia reciente de México, expresada en más de un centenar de programas sociales dirigidos al sector rural. En 1970 México tenía una población de más de 48 millones de personas; los mexicanos que habitaban en zonas rurales eran casi 20 millones y de éstos casi 800 mil no hablaban español. Los programas de María Esther Zuno tuvieron énfasis en cuatro rubros: alfabetización, nutrición, salud y cultura. Fue un personaje relevante en el apoyo a los exiliados chilenos tras el golpe de Estado de Pinochet a Salvador Allende, el 11 de septiembre de 1973.
} 


\section{Metodología}

La revisión documental sobre la temática general de los exilios en México y concreta del exilio chileno fue parte medular de este artículo, así como la política del gobierno mexicano correspondiente. Se utilizó la metodología de la historia oral para incorporar la subjetividad de los exiliados, tomando en cuenta que hablar de exilio es también hablar de exiliados y de las significaciones que éstos le dan a sus experiencias.

Se indagó teóricamente sobre el concepto de poder y la tipología del mismo, con énfasis en el llamado "poder de facto" que ejercen algunos operadores del poder, como algunas esposas de Presidentes. Y es que el poder que las esposas de los Presidentes de México han ejercido de manera real no se ha estudiado a fondo. Incluso, no se contempla, de manera específica, en los distintos tipos de poder que plantean algunos autores como Max Weber (Rivera, 2013, p.1).

$\mathrm{Al}$ analizar los discursos y tomar como guía la tipología de algunos autores como Rivera (2013, p. 5) se dedujo que el "poder de facto" ejercido por la esposa del Presidente de México tenía relación con lo que ese autor denomina "poder de referencia”, el cual supone un proceso de comunicación de carácter emotivo. O, siguiendo a Michel Foucault (Ávila, 2008, pp. 216-217), el poder ejercido por personajes a quienes denomina "operadores del poder", el cual ejercen a discreción y con orientaciones disímbolas.

\section{Los operadores del poder}

Otros enfoques del poder son aquellos que tratan autores como Michel Foucault. Ávila (2008, pp. 216-217) cita a ese teórico quien se refiere a otras concepciones: 1) La jurídica y liberal del poder político, desarrollada por los filósofos del siglo XVIII, 2) la concepción marxista, a la cual le da el nombre de economicismo de la teoría del poder o funcionalidad económica del poder y 3) la que ubica a los "operadores del poder" que controlan las relaciones entre los sujetos, vertiente que aborda desde la idea de lo que tiene el poder de facto y de efectivo y que nos aproxima al tipo de poder que ejerció María Esther Zuno de Echeverría.

Sobre este tercer tipo de poder, Daron Acemoglu y James Robinson (2006, p. 675), hacen dos subclasificaciones: Poder de jure y poder de facto. En el primer caso, quienes ejercen el poder, lo hacen apegados a la legalidad institucional, mientras que quienes utilizan el poder de facto lo hacen basados en su capacidad para resolver dilemas colectivos, al acceso a recursos económicos o al uso de la 
fuerza. La cercanía al poder presidencial y su formación ideológica, hace ver a María Esther Zuno como personaje que ejerció el poder de facto.

\section{Poder, discurso y cotidianeidad}

El poder de María Esther Zuno en el sexenio 1970-1976 incide en los estudios sobre poder, discurso, y cotidianeidad. Alain Touraine (citado por Restrepo, 2010) considera que la relevancia de la vida cotidiana se debe a que ésta actúa como instancia “articuladora de la sociedad” (p. 33). El análisis de hechos de la vida diaria permite, por otra parte, acercarse a la recuperación de momentos históricos singulares, en este caso el exilio chileno en 1973.

El poder ejercido por María Esther Zuno en el ámbito de "lo pequeño" constituyó la concreción de una política de asilo del gobierno mexicano. Restrepo (2010, p. 34) observa que para cada hombre y para cada mujer, "en su cotidianeidad se concreta su vida”, visión que coincide con la de Prieto (2002, p. 72), quien define la vida cotidiana como las concepciones, evaluaciones y percepciones de la realidad que en su diaria práctica comparten los integrantes de un grupo social. Este autor, sin embargo, va más allá: destaca que la suma de pequeñas acciones diarias puede llegar, incluso, a transformaciones sociales y de la microhistoria de los individuos pasar a la macrohistoria. Plantea estas preguntas: ¿Qué hubiese sido de Colón sin carabeleros, de Bolívar sin los llaneros o de la Revolución Francesa sin pueblo?

Hablar de vida cotidiana no significa hablar de funcionalidad. En lo cotidiano se expresan también disfunciones de tal magnitud que la vida cotidiana "está plagada de catástrofes, penurias, carencias” (Prieto, 2002, p.75). Prieto (2002) observa:

Si un individuo debe caminar todos los días más de tres kilómetros para conseguir agua, si le falta permanentemente el pan cotidiano, si no posee los mínimos objetos que le puedan facilitar su relación con el entorno, difícilmente podrá tener una vida cotidiana funcional (p. 76).

\section{El procedimiento y las categorias de análisis}

El análisis del discurso de los exiliados chilenos se realizó tomando como corpus los testimonios y la validez de los mismos con base en los planteamientos de Pardo (2007, pp. 81-82) quien legitima un corpus en relación con un fenómeno sociocultural (en este caso, la condición de exiliados) que permite indagar sobre asuntos "inherentes a sus vidas” y a la reconstrucción de una memoria individual. 
Para Norambuena (2008) se abre paso en los exiliados una noción hasta entonces lejana o ajena, la de "identificación". Es a través de ésta "que es posible distinguir entre el yo, el nosotros y los otros a partir de signos específicos, y situarlos en una realidad determinada" (p. 167).

Tras ubicar el corpus, se ubicaron las categorías de análisis que guiaron la sistematización e interpretación de los testimonios. Prieto (2002, p. 57) señala cuatro funciones básicas en el discurso: indicar, exhortar, explicar, y valorar. Tomando al enunciado como base, considerado como la menor unidad de sentido de un lenguaje. La indicación consiste en enunciados declarativos, en los cuales se señala algo presente o no, visible o no, lo cual

Puede ser reconocido tanto por el emisor del enunciado como por el perceptor del mismo. Lo importante aquí es la forma en que el emisor se coloca frente al objeto señalado. Simplemente lo indica, da cuenta de él[ ...] el acento fundamental de los indicativos está puesto en la referencialidad, es decir, aquello a lo que se alude. Esto no significa que la alusión sea necesariamente verdadera. (Prieto, 2002, p. 58)

Los enunciados de carácter exhor tativo cumplen un papel destacado. Consisten en "pedidos sutiles o en órdenes que se dan a alguien a fin de obtener algo. Los primeros incluyen todo tipo de matices que tienden a suavizar el contenido de la exhortación; los segundos son directos y a veces llevan hasta el abierto autoritarismo" (Prieto, 2002, p. 147). Este tipo de enunciados se encuentran sobre todo en los mensajes publicitarios.

Un tercer tipo de enunciado es el explicativo. Estos enunciados "apuntan a dar cuenta del porqué de algo... Se trata, no de indicar simplemente, de ofrecer un dato, sino de profundizar en él, de dar cuenta de las causas. En los enunciados explicativos hay que reconocer grados. Hay explicaciones superficiales y más profundas. Hay explicaciones parciales y más completas" (Prieto, 2002, p. 149).

Otro tipo de enunciado en el modelo de Prieto es el valorativo, considerado de tipo subjetivo porque involucra los valores concretos del enunciatario. En el caso de los exiliados chilenos, entrevistados más de cuatro décadas después de su exilio en México, implica toda una experiencia de vida y un recuerdo matizado por vivencias directas, una memoria reconstruida. En la categoría de enunciados valorativos, se incluyen aquellos que expresan una resignificación valorativa, consistente en adjudicar una connotación positiva o negativa, según el hablante y el uso que le da al lenguaje. 


\section{Resultados}

Se presentan los resultados en el siguiente orden: 1) Características generales del exilio chileno en México; 2) Características de la política de asilo del gobierno mexicano; 3) Testimonios de siete chilenos entrevistados que dan cuenta de una solidaridad concreta hacia su causa y 4) La implementación de esa política de solidaridad de la Sra. María Esther Zuno de Echeverría.

Aun cuando el exilio chileno tras el golpe de Estado de Augusto Pinochet a Salvador Allende fue de dimensiones mayúsculas, autores como Yankelevich y Tarrés (1998, p. 130) destacan que a diferencia de los chilenos que se asilaron en otros países, en México llegó la élite dirigente y que el aporte mexicano en cuanto a la vida de los chilenos "fue uno de los más altos y sobresalientes".

Dos elementos fundamentales facilitaron la adaptación de los chilenos exiliados a México tras el golpe de Estado del general Augusto Pinochet al presidente Salvador Allende: la política de asilo del gobierno mexicano fundamentada jurídicamente en los principios establecidos en las Convenciones de La Habana (1928), Montevideo (1933) y Caracas (1954), ya que México es un país signatario de ellos. Además, el poder de facto expresado en una solidaridad contundente de la Sra. María Esther Zuno de Echeverría, esposa del presidente de la República Luis Echeverría Álvarez (1970-1976). La conjunción de ambos elementos evidencia, a través de siete testimonios, la forma como aquellos exiliados pudieron adaptarse al país que los acogió y les proporcionó vivienda, trabajo y un nuevo hogar.

Los testimonios presentados fueron explicativos y valorativos. La parte explicativa se registró en la situación personal de cada exiliado. Ellos (los exiliados) consideraron necesario dar a conocer su historia personal, explicar el porqué de su exilio a México. La parte valorativa se expresó en la necesidad de registrar el valor de la solidaridad encontrada en México.

El análisis de los testimonios sigue este orden: Primero se presentaron los datos básicos del testimoniante y enseguida los párrafos elegidos para análisis que indicaron de manera implícita o explícita el sentido de las acciones discursivas ya mencionadas (indicar, exhortar, explicar y valorar) a la cual se añadió la categoría de "identificación" considerada como aquella que permitió a los exiliados identificarse en grados diversos a los modos de vida en México.

En relación con las categorías de discursos indicativo y exhortativo, prácticamente no se detectaron. 
De la recuperación de los testimonios de los chilenos exiliados en México se deduce lo que podría denominarse un "discurso solidario-existencial” expresado en la actitud de refugio de México y de los mexicanos. Por ejemplo:

Andrés Rivera Neveu, quien tenía 24 años de edad cuando ocurrió el golpe de Estado a Salvador Allende, era dirigente del secretariado del Partido Socialista en la empresa de electrodomésticos en la cual trabajaba. Lo llevaron a Puchuncavi, que había sido un Centro Vacacional, transformado por los militares en campo de concentración. Allí sufrió torturas física y sicológica.

"Nos humillaban, se burlaban mientras nos sometían a castigos...Nos tenían sobre la parrilla metálica, amarrados de pies y manos para aplicarnos corriente eléctrica en la lengua, genitales, en los oídos... Decían: - Si tienes algo que informar, levanta un dedo- Entonces venía la descarga eléctrica y a uno se le abrían todos los dedos, por los espasmos. Se reían y nos gritaban: ¡Te dije un dedo, hijo de puta, no los diez;” (Ortúzar, 1993, p. 70).

Andrés estuvo en Puchuncavi siete meses y medio hasta que el 21 de marzo de 1975 llegó a la ciudad de México "solo y sin un peso” (Ortúzar, 1993, p. 71). Esta expresión de Rivera expresa la desesperación del exiliado por llegar a un lugar desconocido sin compañía de ningún tipo y sin recursos económicos.

Tras instalarse en México, Andrés trabajó en el entonces Instituto Nacional de Protección a la Infancia (INPI). Posteriormente, Andrés tuvo dos hijos. Uno de ellos padecía parálisis cerebral. En esa situación especial acudió a la Sra. María Esther Zuno quien dio instrucciones de que el niño fuera atendido en la Institución Mexicana de Asistencia a la Niñez (IMAN), organización que ella dirigía. Al recordar a María Esther Zuno, Andrés expresó:

"Tanto el INPI como el DIF me dieron todas las facilidades del caso para tratar a mi hijo. Eso gracias a que yo contaba con la planta como trabajador — es decir, tenía contrato- todo lo cual, en gran medida, se debió a la actitud profundamente generosa y hasta maternal, diría yo, de la señora María Esther" (citado por Ortúzar, 1993, p. 35).

Este testimonio se inscribe en las categorías de explicativo y valorativo. Al calificar la actitud de María Esther como "profundamente generosa” se deduce que la presidenta de la IMAN conoció y atendió el caso del hijo de Andrés Rivera. El discurso de Rivera va más allá. Califica la actitud de la señora María Esther de “maternal”. Este calificativo tan común en México adquiere otra connotación expresado por un extranjero que llega al país en calidad de exiliado. El término 
“maternal” manifiesta cobijo, abrigo y eso era precisamente lo que los chilenos necesitaban.

La señora Hortensia Bussi viuda de Allende llegó a México al igual que su hija Isabel ${ }^{2}$, quien tenía un niño de cinco años (Gonzalo) y una bebé de meses. Isabel recordaría después que cuando le preguntaron si necesitaba algo, ella pidió una cuna, la cual le fue proporcionada de inmediato. El enunciado de Isabel Allende fue evidentemente no sólo de tipo explicativo sino valorativo por la carga sicológica que implicaba llegar con una bebé y no tener donde dormir (Valles, 2006, p.33)

Un testimonio singular que expresa nítidamente la posición de María Esther Zuno en relación con la llegada de los chilenos es el testimonio de Bertha Zuno, hermana de María Esther, proporcionado a Elías (2007):

"Me llamaron de Los Pinos (la residencia presidencial en México). Cuando llegué, María Esther me dijo: espero que tú si puedas hacer esto que te voy a pedir: están los compañeros chilenos en los hoteles... no traen nada, quiero que vayas allá y les ofrezcas la solidaridad del pueblo mexicano. No es un regalo lo que les vas a hacer, ni una limosna. Y diles que vas de mi parte" (Elías, 2007, p. 145).

Los chilenos vivieron primero en el hotel del Bosque y en el San Diego. Posteriormente fueron trasladados a una unidad habitacional en Iztapalapa. Allí les regalaron muebles, una vajilla, algunos equipales. María Esther, cuenta Bertha Zuno (2006, p. 133) iba a visitarlos con frecuencia.

Carlos Ovando (citado por Valles) otro exiliado chileno, recuerda que Bertha Zuno, La Chiqui, le presentó a su hermana María Esther, quien le regaló una guitarra "muy buena por cierto"

2. La relación de María Esther Zuno con Chile se inició a través de Hortensia Bussi, esposa del presidente de Chile Salvador Allende. En agosto de 1971 un sismo de gran intensidad sacudió a Chile. La ayuda del gobierno mexicano se hizo llegar por medio de la esposa del presidente de México. María Esther consolidó su amistad con el matrimonio Allende En 1973, cuando se registró una gran inundación en Irapuato (México), el presidente Salvador Allende le escribió una carta personal a María Esther, en la que expresó el "afecto invariable y solidario de Chile y sus gentes, en estas horas amargas y duras para México, para ustedes y su pueblo" (Elías, 2007, pp. 143-144). El presidente Allende escribió: Entre nosotros, María Esther, está vivo y tibio el recuerdo de su presencia en las horas tensas del terremoto. Usted fue el símbolo bondadoso que México y su Presidente nos enviara como expresión de fraternal amistad. Desde ese día, se han hecho más profundos y anchos los vínculos que siempre han unido a nuestros países. ...Nos unió el sufrimiento y nos une la esperanza cierta de mejores horas para nuestros pueblos que luchan por su plena independencia. Juntos hemos derramado lágrimas de piedad y de trabajo, atadura histórica que no se rompe, que tiene la fuerza del sentimiento y la fuerza de la convicción... (Elías, 2007, pp. 143-144) 
"Con esa guitarra animábamos nuestras noches de tertulia en el hotel Versalles, a donde nos habían mudado (primero estuvieron en el Hotel de la Ciudad de México)... Con esa guitarra espantábamos la nostalgia en las noches de Iztapalapa, adonde fuimos después, a vivir más independientes" (Carlos Obando, exiliado chileno, citado por Valles, 2006, p. 139).

En el enunciado anterior se, mezclan dos categorías: una organizativa (enunciado explicativo) y otra de tipo estilístico: la inclusión. Ésta, consiste en el involucramiento del sujeto de la emisión en una acción concreta. Este recurso constituye en realidad una manera de reconocimiento, de integración social.

En la expresión de Ovando, la inclusión de la primera persona del plural expresaba el sentido de grupo de un grupo de exiliados que fuera de su Patria, luchaban por encontrar puntos de coincidencia en la cotidianidad. Animábamos nuestras noches de tertulia, expresa. Y más adelante Espantábamos la nostalgia. El enunciado es explicativo. Expresa, sin decirlo explícitamente, la necesidad de "animar" las noches. Implícitamente expresa que había en todos ellos un sentido de nostalgia que remitía al drama existencial que vivían, el cual "espantaban” a través de la guitarra regalada a Ovando por María Esther. Luchaban por pertenecer a una nueva Patria y encontraban en un objeto musical el instrumento idóneo de cohesión.

\section{El valor de los símbolos}

La expresión de Ovando al referirse a la guitarra remite también al valor de los símbolos en la cotidianidad. Los símbolos, señala Herrero (2006) cuando son verbalizados, adquieren otra dimensión. Cuando el sujeto es capaz de simbolizar, observa, "no es nunca un solo individuo, sino una sociedad histórica” (pp. 172-184).

Los símbolos pueden ser objetos, palabras, frases. Y los objetos pueden traducirse en conceptos, en estímulos sicológicos, un apretón de manos, una caricia, una sonrisa, una palmada en situaciones extremas significan un apoyo a un discurso existencial viviente. La explicación y la valoración se encuentran explícita e implícitamente en los testimonios de otros chilenos exiliados en México como el de Ortúzar (1999) quien, tras la muerte de María Esther Zuno de Echeverría, en 1999, la recordó así:

“[...] Innumerables cosas tengo que agradecerle. Por principio de cuentas, las camas de mis hijos, que no pudimos adquirir porque salimos de Chile con los sueños rotos y la ropa que llevábamos puesta, confesos y convictos de perseguir utopías. Pero por sobre todo tengo que agradecerle su inquebrantable lealtad a sus ideales y a sus 
amigos, entre los que estaba el presidente Salvador Allende. Lealtad que mantuvo intacta hasta el momento de su partida. No es poco decir en época de fin de siglo, en que la lealtad, como otros valores y principios, no son transables en los mercados financieros y, por tanto, el pragmatismo posmodernista los considera inútiles y desechables" (Ortúzar, 1999, p. 114).

¿Discurso de explicación? ¿Exhortación? ¿Valoración? Evidentemente una mezcla de todos ellos tras las emociones expresadas por Ortúzar en las cuales se entretejen los recuerdos de una salida abrupta de su país "con los sueños rotos y la ropa que llevábamos puesta, confesos y convictos de perseguir utopías".

La segunda parte del testimonio de Ortúzar (1999) puede clasificarse ampliamente en la categoría de valorativo, al reconocer la lealtad de María Esther hacia "sus ideales y a sus amigos, entre los que estaba el presidente Salvador Allende. Lealtad que mantuvo intacta hasta el momento de su partida."

La también difícil salida de Rogelio de la Fuente de Chile es registrado por Valles (2006) así:

Él era diputado federal en el gobierno de Allende. Tras el golpe de Pinochet se percató de la imposibilidad de permanecer en Chile porque su vida estaba en riesgo. Intentó asilarse con su familia en la embajada de República Dominicana. Cuando se acercó y pidió asilo, una joven gritó desde el jardín: ipolicía, policía, aquí hay gente! Ellos huyeron arrancando el coche en el que llegaron. La angustia crecía. El nombre de Rogelio de la Fuente aparecía en los diarios de Santiago como cabeza de un grupo que aseguraban, estaba organizando una revolución armada. Su esposa, con ocho meses de embarazo, y su hijo, de un año de edad, se escondieron en la casa de unos parientes pero tuvieron que dejar la casa de éstos cuando se enteraron de allanamientos cercanos. Cuando pensaron en pedir asilo en la embajada de México, realizaron una acción audaz. Un amigo distrajo a los policías encargados de cuidar la sede diplomática, instantes aprovechados para entrar. Los vigilantes, al percatarse de la treta, intentaron impedirles la entrada pero Rogelio de la Fuente, ya con su esposa e hijo adentro y con medio cuerpo de él entre la puerta de la Embajada de México y la calle, gritó desgarradoramente: ¡Estamos en territorio mexicano! (Valles, 2006, p. 73).

Una frase emotiva. Un grito doloroso e incluyente. ¡Estamos en territorio mexicano! significó el discurso de salvación para aquella familia; Rogelio de la Fuente recordó que tras la estadía en la embajada, él y su familia por fin pudieron abordar el avión que los llevaría a México. Sobre el viaje reflexionó: 
"Nos dieron whisky. Primero me desconcerté, luego supe que con gran sensibilidad los mexicanos habían hecho eso para anestesiar un poco la emoción. Todos tomamos tragos ahí, el avión partió; a las dos, tres horas de vuelo, el capitán anunció: — “vamos cruzando la frontera de Chile con Perú, abandonamos Chile en este momento”- Yo me abracé llorando a mi mujer" (testimonio de Rogelio de La Fuente).

Para Rogelio y su familia, instalarse en México no fue fácil. Sin embargo, se encontraron con la generosidad de María Esther Zuno de Echeverría:

“...ella personalmente nos llevó ropa. Mi esposa no tenía que ponerse, sólo lo que traía puesto. Nos llevó una maleta y ropa. Y la maleta en la chapa tiene iniciales LEA (Luis Echeverría Álvarez)... La guardamos como reliquia, así como una silla que estaba en el departamento donde vivimos en Ermita Iztapalapa” (testimonio de Rogelio citado por Valles, 2012, p. 76).

En este testimonio surge el valor de los símbolos: Rogelio de la Fuente guarda una maleta y una silla como recuerdo de la solidaridad mexicana.

Las categorías de explicación y valoración se aprecian en otros testimonios. Andrés Rivera Neveu, quien regresó a Chile tras la restauración de la democracia, contesta cuando le preguntan cómo le fue en el exilio en México y si hubiera elegido otro país:

"Si tuviera que optar por un país, elegiría México. Libremente. Siempre lo digo a quienes preguntan qué nos dejó el exilio: tuvimos 14 años para extrañar a Chile y ahora el resto de la vida para extrañar a México" (testimonio de Andrés Rivera citado por Ortúzar, 1999, p. 119)

Klelya Meza relató a Valles (2006) su salida de Chile y su inserción en México. Ella trabajaba como asistente doméstica con el señor José Toha, vicepresidente de Salvador Allende, quien fue detenido tras el golpe de Estado del 11 de septiembre. Tras la muerte de Toha, Klelya siguió trabajando con Moy, la esposa de José Toha.

"Después del golpe seguí saliendo a la calle, ver a muchas personas, llevar y traer cosas. Un día, en la calle, unos carabineros me reconocieron. Ellos habían montado guardia en la puerta de la casa de los Allende...La cosa no quedó ahí. Los milicos ${ }^{3}$ fueron agresivos al punto de decirme: Te vamos a matar por comunista, con la misma metralleta de Allende” (testimonio de Kleyla Meza citado por Valles, 2006, p. 77). 
La familia de José Toha estaba destruida. Moy (la esposa) decidió exiliarse en México. Le preguntó a Klelya si la acompañaría y la angustia que ya vivía Klelya le hizo contestar de inmediato que sí. "Yo no lo pensé dos veces porque estaba muy aturdida. Me había afectado mucho la muerte del doctor, la de don José y la prisión de tantas otras personas" (Ortúzar, 1993, p. 122).

Así, Klelya llegó a México donde trabajó con Moy de Toha aunque posteriormente conoció a la señora Echeverría y colaboró directamente con ella. De su relación con la esposa del Presidente de la República conversó con Valles (2006) y recordó:

"La señora María Esther era una persona seria pero eso era por las obligaciones que tenía no por ser con la gente tirana ni mala; al contrario, era muy accesible, una persona que escuchaba, por lo menos el tiempo que yo la conocí es la imagen que yo tengo de ella y siempre me han dolido los malos comentarios. Porque la señora María Esther que yo conocí no era como los comentarios que hacían muchas personas. Yo escuchaba que siempre la estaban criticando la vestimenta, qué cómo se vestía, cómo se presentaba, ella lo único que hacía era mostrar la artesanía mexicana, vestidos típicos mexicanos que son preciosos. A mí me encantan esos vestidos" (testimonio de Kleyla citado por Valles, 2006, pp. 79-80).

En cuanto al trato directo con la esposa del presidente, Klelya comentó que era una persona que trataba muy bien a su personal mexicano "y a mí también me incluía en ese grupo" (Valles, 2006, p. 81).

Posteriormente Klelya es invitada por el matrimonio Echeverría-Zuno a Australia, donde el expresidente mexicano se desempeñó como embajador. Recuerda que la esposa del exmandatario atendía "a toda la gente que acudía a la embajada en busca de ayuda. Siempre pendiente de solucionar todos los problemas, de proveer todo lo que fuera necesario" (Valles, 2006, p. 82).

\section{Conclusiones}

La política de asilo del gobierno mexicano facilitó el ingreso de los chilenos desterrados de su país tras el golpe de Estado de Augusto Pinochet el 11 de septiembre de 1973. Estimaciones de Elías (2007, p. 135) consideran cerca de 4

4. María Esther Zuno de Echeverría fue duramente criticada por las clases medias acomodadas y las clases altas por su forma de vestir. Portaba trajes regionales con orgullo y ofrecía agua de Jamaica y horchata en las recepciones oficiales en Palacio Nacional. 
mil los chilenos que llegaron a México y encontraron trabajo, vivienda y respeto. Esta cifra no coincide con la dada a conocer por Gonzalo Martínez Corbalá, embajador de México en Chile durante el gobierno de la Unidad Popular. Martínez Corbalá afirma que fueron 2 mil 400 chilenos con sus familias, lo que daría un total aproximado de 10 mil personas.

La coincidencia en ideales políticos de María Esther Zuno con el presidente Salvador Allende y su esposa Hortensia Bussi, así como del gobierno mexicano, expresada en acciones de solidaridad hacia Chile en el terremoto de 1973 y de Chile hacia México en la inundación registrada en Irapuato asentada en cartas mencionadas en este artículo, en las que expresan sus coincidencias políticas, facilitó el apoyo a los chilenos en todos los ámbitos, laboral, económico y personal.

El poder de facto que ejerció María Esther Zuno permitió que los chilenos recibieran apoyos básicos para instalarse en México, país con el que se identificaron en distintos aspectos y donde desarrollaron su vida personal y profesional. El discurso de solidaridad de la Sra. Zuno de Echeverría se materializó en hechos tangibles que hicieron que la llegada de los exiliados fuera más tersa. Esta posición fue congruente con la realizada a lo largo del sexenio 1970-1976: al implementar más de cien programas sociales en apoyo a las clases marginadas.

La reconstrucción de significados de la estancia en México por parte de los chilenos expresó un discurso explicativo y de valoración que manifestó una solidaridad cuya incidencia en la vida cotidiana fue de gran importancia.

El análisis del discurso, a través de las categorías de Prieto (2002) resultó una herramienta metodológica idónea para reconocer la existencia de un discurso explicativo y valorativo de solidaridad de los exiliados chilenos, como se manifestó en el objetivo de este trabajo

\section{Referencias}

Acemoglu, D. y Robinson, J. (2006). Paths of Economic and Political Development. En Weingast, Barry y Donald Wittman, eds., The Oxford Handbook of Political Economy, New York, Oxford University Press,

Ávila, F. (agosto, 2006). El concepto de poder en Michel Foucault. Telos, 8(2), Venezuela, Universidad Rafael Belloso Chacín. 
Castro, P. (2004). El último caudillo. Polis O3(2), México.

Del Pozo, José (2004). Los chilenos en el exterior: ¿De la emigración y el exilio a la diáspora? El caso de Montreal. Recuperado de http://remi.revues. org/4968? lang=en

Elías, M. P. (2007). La Compañera, María Esther Zuno de Echeverría. México: ¡Buena idea! Editores, S.A. de C. V.

Franco, M. (2014). El exilio político chileno: La casa de chile en México (1973-1993), una experiencia singular. (Tesis de doctorado en estudios americanos). Recuperado de http://190.98.219.232/ tesisdh/Tesis_PDF/Tesis\%20 Rojas\%2oClaudia.pdf

Gala, A. (1985) Un álbum de familia. De Juan y Peñalosa, J. Historia Ilustrada del Siglo XX, México: Editorial Cumbre.

Herrero, M. (2006). Símbolos políticos y transiciones políticas. Athenea Digital (10). México.

Meyer, E. y Salgado E. (2002). Un refugio en la memoria. La experiencia de los exilios latinoamericanos en México. México: UNAM-Océano.

Norambuena, C. (2008). El exilio chileno. Río profundo de la cultura iberoamericana. Sociohistórica: Cuadernos del CISH (23-24), 161-195.

Ortúzar, J. (1993). El exilio chileno en México. (Inédito). (Reproducción con la autorización de la autora).

Palacios, V. (2004). El concepto de poder en Hanna Arendt. Revista Humanidades de la Universidad de Montevideo. Recuperado de: :http://www.um.edu.uy/_upload/_ publicacion/_archivos/web_publicacion_62_HUMANIDADES_3.pdf

Palma, M. (2003). Destierro y encuentro. Aproximaciones al exilio latinoamericano en México 1954-1980. Recuperado de: www.alhim.revues.org/document363.html.

Prieto, D. (2002). Diseño y comunicación. México, Ediciones Coyoacán.

Restrepo, M. (2010). Una semántica de lo cotidiano. Revista Chasqui(36). Recuperado de: www.chasqui.com. 
Rivas, J. M. (2012). Liderazgo y gobernabilidad política en América Latina. Una aproximación teórica y metodológica. Recuperado de: http://americo.usal. es/iberoame/sites/default/files/rivas_PAPERseminario5_2012-2013.pdf.

Rivera, A. (2013) Los tipos de dominación según Max Weber. Revista Plural. Recuperado de http://fcsyp.mxl.uabc.mx/RevistaPlural/descargas/Edicion3/angel-riveraokya.pdf.

Rojas, C. (junio, 2014). Exilios sudamericanos en México: los casos argentino y chileno. Pacarina del Sur, 5(19). Recuperado de: www.pacarinadel sur. comindezpho? optioncom:

Rojas, C. y Santoni, A. (Junio, 2013). Geografía política del exilio chileno. Los diferentes rostros de la solidaridad. Perfiles Latinoamericanos, (41).México, FLACSO.

Salgado, E. (2003). El discurso del poder. Informes presidenciales en México (1917-1946) México: CIESAS-Miguel Ángel Porrúa.

Ubeira, A. (2005). El poder de las mujeres en Susana Pérez Gallart. El poder de las mujeres, Comisión Derechos de La Mujer y los derechos, Buenos Aires, Asamblea permanente por los derechos humanos; Fundación Ebert-

Valles, R. M. (1995). La legitimación social de la opinión periodística. (Tesis de Maestría, inédita). Universidad Nacional Autónoma de México.

Valles, R. M. (2006). Yo no soy Primera Dama. Biografía no autorizada de María Esther Zuno de Echeverría, México, DEMAC.

Yankelevich, P. y Tarrés, M. L. (1998). En México, entre exilios: una experiencia de sudamericanos. Recuperado de: razon.com.mx.

\section{Entrevistas}

De la Fuente. R. (2009). Entrevista con Rosa María Valles Ruiz. Ciudad de México.

Meza, Klelya (2006). Entrevista con Rosa María Valles Ruiz. Ciudad de México.

Ortúzar, X (2008) Entrevista con Rosa María Valles Ruiz. Ciudad de México. 
Ovando, C. (2007) Ovando. Entrevista con las autoras de este artículo. (Vía correo electrónico).

Rivera, (2009). Entrevista con Ximena Ortúzar. Publicación inédita.

Salgado, E. (2015) Entrevista con Rosa María Valles Ruiz. Ciudad de México.

\section{Otros documentos}

Ximena Ortúzar. Carta dirigida a María Esther Zuno de Echeverría. Revista Proceso, Diciembre de 1999. En Elías Salazar, María del Pilar (2007). La Compañera, María Esther Zuno de Echeverría. México: ¡Buena idea! Editores, S.A. de C.V. 